\title{
Atherosclerosis in Renal Failure
}

Key words: IMT, hemodialysis, dyslipidemia

Physicians in hemodialysis units know well about advanced atherosclerosis in renal patients, whereas this serious health problem may not be so widely known by doctors with other specialties. Patients undergoing hemodialysis are at an unacceptably increased risk of death from cardiovascular disease, and the relative risk is 10 to 20 (1) as compared with the general population. Hemodialysis patients have increased thickness (2), stiffness (3) and calcification of large arteries. Factors contributing to the advanced arterial changes include endocrinological and metabolic alterations secondary to renal failure.

In this issue of the Journal, Nakamura et al (4) reported a unique analysis of different measurement methods of atherosclerosis by B-mode ultrasound in hemodialysis patients. They measured intima-media thickness (IMT) of the carotid artery at several cites bilaterally, and determined the maximum IMT including plaque if any, and the mean IMT of plaque-free arterial segments. The independent risk factors for the maximum IMT were age, the presence of diabetes mellitus, smoking and intact parathyroid hormone (PTH) level, whereas the risk factors for the mean IMT were age, hypertension, dyslipidemia, intact PTH and lipoprotein (a) level.

See also p 1095.

This study has at least three implications. First, this study confirmed the importance of secondary hyperparathyroidism in arterial wall changes in hemodialysis patients (2) by showing it as one of the common risk factors of the two different measurements of arterial morphology. It would be an attractive hypothesis that the appropriate use of phosphate binders and vitamin D may be of survival advantage in patients undergoing hemodialysis.

Second, this study provides information on the methodological issue of IMT measurement. Different researchers have used either the mean (5) or maximum IMT values (6) to express morphological changes in the carotid arteries, although it is unknown which is better in assessing arterial morphology. Nakamura et al showed the difference in risk factors associated with the mean and maximum IMT values, suggesting a pathophysiological difference in these arterial parameters. Although both mean (5) and maximum IMT (6) of the carotid artery are reported to be predictive of cardio- vascular mortality, no comparative study has been performed to examine a possible difference in their predictive value in hemodialysis patients.

Third, this study adds another piece of evidence that dyslipidemia is closely associated with arterial wall changes in hemodialysis patients (7). There has been discussion on the role of dyslipidemia in atherosclerosis of hemodialysis patients, because a higher plasma cholesterol level was known to be a predictor of a better survival rate in hemodialysis patients (8). The unusual relationship between cholesterol and mortality is called 'reverse epidemiology' or 'risk factor paradox' (9). Malnutrition is another important factor affecting survival in renal failure, and it also interacts with other risk factors including plasma lipids. One of the interpretations is that dyslipidemia itself is bad for arteries and cardiovascular events, whereas poor nutritional conditions that may present low plasma lipids may be disadvantageous for survival once some events occur. Ongoing clinical trials with statins in dialysis patients (10) will indicate whether or not we should reduce plasma lipids in this special population.

Tetsuo SHOJI MD, PhD and Yoshiki NishizAwa MD, PhD Department of Metabolism, Endocrinology and Molecular Medicine, Osaka City University Graduate School of Medicine, 1-4-7 Asahi-machi, Abeno-ku Osaka 545-8585

\section{References}

1) Foley RN, Parfrey PS, Sarnak MJ. Epidemiology of cardiovascular disease in chronic renal disease. J Am Soc Nephrol 9: S16-S23, 1998.

2) Kawagishi $T$, Nishizawa $Y$, Konishi $T$, et al. High-resolution B-mode ultrasonography in evaluation of atherosclerosis in uremia. Kidney Int 48: 820-826, 1995.

3) London GM, Marchais SJ, Safar ME, et al. Aortic and large artery compliance in end-stage renal failure. Kidney Int 37: 137-142, 1990.

4) Nakashima A, Yorioka N, Asakimori Y, et al. Different risk factors for the maximum and the mean carotid intima-media thickness in hemodialysis patients. Intern Med 42: 1095-1099, 2003.

5) Benedetto FA, Mallamaci F, Tripepi G, Zoccali C. Prognostic value of ultrasonographic measurement of carotid intima media thickness in dialysis patients. J Am Soc Nephrol 12: 2458-2464, 2001.

6) Nishizawa Y, Shoji T, Maekawa K, et al. Intima-media thickness of carotid artery predicts cardiovascular mortality in hemodialysis patients. Am J Kidney Dis 41: S76-S79, 2003.

7) Shoji T, Nishizawa Y, Kawagishi T, et al. Intermediate-density lipoprotein as an independent risk factor for aortic atherosclerosis in hemodialysis patients. J Am Soc Nephrol 9: 1277-1284, 1998.

8) Iseki K, Yamazato M, Tozawa M, Takishita S. Hypocholesterolemia is a significant predictor of death in a cohort of chronic hemodialysis patients. Kidney Int 61: 1887-1893, 2002. 
9) Kalantar-Zadeh K, Block G, Humphreys MH, Kopple JD. Reverse epidemiology of cardiovascular risk factors in maintenance dialysis patients. Kidney Int 63: 793-808, 2003.

10) Wanner C, Krane V, Ruf G, Marz W, Ritz E. Rationale and design of a trial improving outcome of type 2 diabetics on hemodialysis. Die Deutsche Diabetes Dialyse Studie Investigators. Kidney Int Suppl 71: S222-S226, 1999. 